\title{
Pharmacokinetic studies and anticancer activity of curcumin-loaded nanostructured lipid carriers
}

\author{
FENGLING WANG ${ }^{1,2, a}$ \\ JIN CHEN ${ }^{1, a}$ \\ WENTING DAI ${ }^{1}$ \\ ZHENGMIN HE ${ }^{1}$ \\ DANDAN ZHAI ${ }^{1}$ \\ WEIDONG CHEN $2, *$ \\ ${ }^{1}$ Department of Pharmacy \\ The Second People's Hospital of Hefei \\ Hefei 230011, Anhui \\ People's Republic of China \\ ${ }^{2}$ Institute of Pharmacokinetics \\ Anhui University of Chinese Medicine \\ Hefei 230012, Anhui \\ People's Republic of China
}

Accepted March 19, 2017

Published online April 10, 2017

\begin{abstract}
In order to investigate the potential of nanostructured lipid carriers for efficient and targeted delivery of curcumin, the pharmacokinetic parameters of curcumin-loaded nanostructured lipid carriers (Cur-NLC) were evaluated in rats after a single intraperitoneal dose of Cur-NLC. In addition, the anticancer activity of Cur-NLC against human lung adenocarcinoma A549 cells was verified by a cellular uptake study, and a cytotoxicity and apoptosis assay. Bioavailability of Cur-NLC was better than that of native curcumin $(p>0.01)$, as seen from the area under the plasma concentration-time curve $(A U C)$, maximum plasma concentration $\left(C_{\text {max }}\right.$, mean residence time (MRT) and total plasma clearance $\left(\mathrm{CL}_{\mathrm{z}} / \mathrm{F}\right)$. Cur-NLC has a more obvious lung-targeting property in comparison with native curcumin. Cur-NLC showed higher anticancer activity in vitro against $\mathrm{A} 549$ cells than native curcumin (IC $C_{50}$ value of 5.66 vs. $9.81 \mathrm{mg} \mathrm{L}^{-1}$, respectively). Meanwhile, Cur-NLC treated A549 cells showed a higher apoptosis rate compared to that of native curcumin. These results indicate that NLC is a promising system for the delivery of curcumin in the treatment of lung adenocarcinoma.
\end{abstract}

Keywords: curcumin, nanostructured lipid carriers, pharmacokinetic, anticancer effects, lung adenocarcinoma

Lung cancer is by far the most frequent cause of cancer-related deaths worldwide (1). The effectiveness of chemotherapeutic agents is often limited by the unavoidable toxicity of drug treatment. It is therefore essential to discover potential agents with more efficient therapeutic strategies and less severe side effects for the treatment of lung cancer. Phytochemicals have been gaining increasing attention as chemopreventive agents to treat various diseases, including lung cancer. Curcumin $\left(\mathrm{C}_{21} \mathrm{H}_{20} \mathrm{O}_{6}\right)$, a hydrophobic polyphenol, is an important phytochemical compound that gives the Asian spice turmeric its light yellow color. It is derived from the rhizome of Curcuma longa and has been long used as food color

\footnotetext{
a These authors have equally contributed to this work.

*Correspondence; e-mail: anzhongdong@126.com
} 
or for medication purposes worldwide, especially in India and other East Asian countries. $77 \%$ curcumin I (diferuloylmethane), $17 \%$ curcumin II (demethoxycurcumin) and $3 \%$ curcumin III (bis-demethoxycurcumin) are the three major constituents of curcumin. Studies have indicated that curcumin has cancer preventive activity, either alone or in combination with other anticancer agents. Curcumin's widespread availability, safety, low cost and multiple cancer fighting functions make it a promising drug for the treatment of numerous cancers, including lung, cervical, breast, hepatic, pancreatic and colon cancer $(2-5)$. The most attractive and vital reason for the therapeutic use of curcumin is its superior safety profile. It has been demonstrated that curcumin has very low toxicity, even at very high doses (6). Nevertheless, native curcumin cannot reach the therapeutic target in a therapeutic concentration because of its low bioavailability. Therefore, curcumin should be formulated in such a way that it can overcome these critical issues. In the current study, nanoformulations of curcumin have been designed with the aim of improving curcumin physicochemical and pharmacokinetic properties (7).

The solid lipid nanoparticle (SLN) has received much attention as an efficient and nontoxic carrier delivery system. SLN has numerous advantages, which include targeted drug delivery, increased stability and solubility of the incorporated drug (8). Nanostructured lipid carrier (NLC) is the second-generation of SLN. As a novel drug delivery system, NLC can improve release properties, reduce drug expulsion during storage and increase the chemical stability of incorporated drugs $(9,10)$. Furthermore, NLC can be formulated for various administration routes, including oral, pulmonary, intravenous, and percutaneous (11). In our early study, Cur-NLC was prepared successfully by the emulsion-evaporation and low temperature-solidification technique. Water solubility of Cur-NLC was better than that of native curcumin. In addition, drug entrapment efficiency and loading capacity of Cur-NLC were both adequate (12).

Intraperitoneal (i.p.) administration of curcumin-loaded NLC has not been investigated to date. Several studies have shown that curcumin nanoparticles have anticancer properties (13). Recent studies have reported that curcumin has shown potential therapeutic value in lung cancer. The chemopreventive effect of curcumin was largely based on its effectiveness to inhibit cell proliferation and induce cancer cell apoptosis (14). The purpose of this study is to investigate the pharmacokinetics of curcumin after i.p. administration of Cur-NLC in rats. In addition, we evaluated the in vitro anticancer activity of Cur-NLC against the human lung adenocarcinoma cell line A549.

\section{EXPERIMENTAL}

\section{Materials}

Curcumin (purity $>98 \%$ ) was purchased from Sinopharm Chemical Reagent Co., Ltd., China. Monostearin (MS) was obtained from Hunan Erkang Pharmaceutical Co., Ltd., China. Tween-80 was purchased from Sonopharm Chemical Reagent Co., Ltd., China. Lecithin and octyl decyl acid triglycerate were provided by Anhui Fengyuan Pharmaceutical Co., Ltd., China. Poloxamer 188 (Pluronic F68) was purchased from BASF (Germany). Methanol (Merck, Germany) was of HPLC grade. RPMI-1640 medium, defined fetal bovine serum (FBS), and $1 \%$ penicillin-streptomycin were obtained from Gibco (USA), while dimethyl sulfoxide (DMSO), sodium carboxymethylcellulose (CMC-Na), 2,5-diphenyltetra- 
zolium bromide (MTT) were purchased from Sigma-Aldrich (USA). Annexin V-fluorescein isothiocyanate/propidium iodide (Annexin V-FITC/PI) was purchased from Nanjing KeyGen Biotech Co., Ltd., China. The human lung adenocarcinoma cell line A549 was obtained from the Institute of Biochemistry and Cell Biology, Institute for Biological Sciences, Chinese Academy of Science (Shanghai, China). Water used was doubly distilled and all other chemicals were of analytical grade.

\section{Preparation of Cur-NLC}

Cur-SLN was formulated using the fast emulsification and low temperature-solidification technique, which was described in detail in our previous study (12). Based on the Cur-SLN formulation procedure, Cur-NLC was formulated by adding additional liquid lipid (octyl decyl acid triglycerate) into Cur-SLN. This is the only difference between CurNLC and Cur-SLN, while their other materials are the same. In brief, the lipid phase and the lipophilic surfactant were dissolved in a modest amount of organic solvent and then heated. After adding curcumin, the hot lipid phase was added into the water solution of hydrophilic surfactant, heated and stirred at $10000 \mathrm{rpm}$ for $2 \mathrm{~h}$ to obtain a pre-emulsion. The resulting hot o/w nanoemulsion was dumped into ice cold distilled water using an electric stirrer (DF-1 Electric Stirred, Jintan, China) and stirred for $2 \mathrm{~h}$. Cur-NLC was formed by lipid recrystallization. The solid lipid, liquid lipid and the surfactants were optimized using a single factor analysis and orthogonal test (15). The optimal formula and technique: the ratios of drug to lipid, liquid lipid to total lipids, lecithin to total lipids, surfactant to water phase and Pluronic F68 to Tween-80 were 1:20, 1:10, 1:50, 3:100, and 1:1, respectively. Organic solvent consisted of ethanol and acetone $(1: 4, V / V)$. The ratio of nanoemulsion to ice cold distilled water was 1:3 $(V / V)$. The physicochemical properties including particles size, polydispersity index (PI) and zeta potential were determined by photon correlation spectroscopy with a Zetasizer (Nano ZS90, Malvern, UK) at $25^{\circ} \mathrm{C}$, after appropriate dilution with ultrapure water. Encapsulation efficiency (EE) and drug loading capacity (LC) of Cur-NLC were assessed indirectly by HPLC analysis. The particles size, polydispersity index (PI), zeta potential, EE and DL capacity of Cur-NLC were $99.99 \mathrm{~nm}$, $0.158,-19.9 \mathrm{mV}, 97.86 \%$, and $4.35 \%$, respectively. Empty NLC were formulated following the same procedure as for Cur-NLC without adding curcumin.

\section{Pharmacokinetic studies}

Animals and dosing. - Healthy SPF Sprague-Dawley male rats $(230 \pm 20 \mathrm{~g})$ were supplied by the Experimental Animal Center of Anhui Medical University (Hefei, China). Rats were allowed to eat a standard diet and drink ad libitum. They adapted to the experimental conditions of $20 \pm 2{ }^{\circ} \mathrm{C}$, humidity $60 \pm 5 \%$ with a 12-hour light/dark cycle. All protocols involving experimental animals were approved by the Institutional Animal Care and Use Committee for Experimental Animal Center, Anhui Medical University, China. The study was approved by the animal-related ethics regulations of Anhui Medical University, China.

After 1 week of acclimation with free access to regular rodent food and water, all rats were randomly and equally divided into two groups for Cur-NLC and native curcumin i.p. administration, respectively. One group of rats (group $1, n=6$ ) received a single dose of $40 \mathrm{mg} \mathrm{kg}^{-1}$ native curcumin suspension (diluted in $0.5 \%$ CMC-Na) by i.p. injection, while the other group of rats (group 2, $n=6$ ) received the same dose of curcumin in Cur-NLC. 
After administration, serial blood samples $(0.3 \mathrm{~mL})$ were collected into heparinized polyethylene tubes at determined time points $(5,10,15,30,45,60,90,120,240$ and $360 \mathrm{~min})$. All blood samples were then centrifuged for $15 \mathrm{~min}$ at 3,000 rpm and $4{ }^{\circ} \mathrm{C}$ to obtain the plasma. Following i.p. administration for $360 \mathrm{~min}$, tissues of interest (heart, liver, spleen, lung, kidney, brain, stomach and small intestine) were collected immediately, lightly rinsed with normal saline and dried with tissue paper. All plasma samples and tissues were frozen at $-80^{\circ} \mathrm{C}$ until further analysis.

Plasma and tissue sample analysis. - The concentration of delivered curcumin was determined by HPLC analysis. A $0.2 \mathrm{~mL}$ plasma sample was extracted and homogenized with $300 \mu \mathrm{L}$ of methanol (to enhance curcumin extraction), and was vortex-mixed for $4 \mathrm{~min}$. The resulting solution was centrifuged at $3000 \mathrm{rpm}$ for $15 \mathrm{~min}$. The supernatant was collected into another clean test tube and evaporated under a stream of nitrogen at $45^{\circ} \mathrm{C}$. The residue was then redissolved using $500 \mu \mathrm{L}$ mobile phase and was filtered through a $0.22 \mu \mathrm{m}$ filter membrane. $20 \mu \mathrm{L}$ of filtrate was injected into the HPLC system to determine curcumin in plasma samples. Plasma concentration can be calculated with the aid of the drug concentration-peak areas standard curve. The plasma concentration-time data were analyzed and the pharmacokinetic parameters, including $A U C, M R T, C_{\text {max }}$ peak time $\left(T_{\max }\right)$ and $\mathrm{CL}_{\mathrm{z}} / \mathrm{F}$, were estimated.

Tissue (30-50 mg) samples were weighed and homogenized using a glass tissue homogenizer after addition of $1 \mathrm{~mL}$ of physiologic saline. The process of tissue homogenates was similar to that of plasma samples and analyzed by HPLC.

Serum and tissue samples were all prepared using a Shimadzu LC-15C HPLC system (Shimadzu, Japan) with a variable wavelength UV detector and LC-Solution Lite Chinese chromatography data system (Agilent Technologies, China).

Curcumin III, used as internal standard, was dissolved in methanol $\left(10 \mu \mathrm{g} \mathrm{mL}{ }^{-1}, 10\right.$ $\mu \mathrm{L})$. Detection conditions were set as follows: Kromasil C18 column $(5 \mu \mathrm{m}, 4.6 \mathrm{~mm} \times 150$ $\mathrm{mm})$ at $25^{\circ} \mathrm{C}$. The mobile phase of methanol and water $(52: 48, V / V)$ was used for chromatographic separation at a flow rate of $1.0 \mathrm{~mL} \mathrm{~min}^{-1}$. Curcumin content in each sample was quantified at $242 \mathrm{~nm}$. The detection limit was $0.03 \mathrm{mg} \mathrm{kg}^{-1}$ for each tissue. Analytical method for measuring curcumin levels in tissue homogenates (heart, liver, spleen, lung, kidney, brain, stomach and small intestine) was as follows. The limit of quantification in tissue for curcumin measurement was $0.01 \mu \mathrm{g} \mathrm{mL}^{-1}$ and the standard curves ranging from $0.01-50$ $\mu \mathrm{g} \mathrm{mL} \mathrm{L}^{-1}$ demonstrated good linearity $\left(R^{2} \geq 0.998\right)$. Interday and intraday precisions were $3.3-4.7 \%$ and $2.7-4.1 \%$, respectively. The recovery of curcumin in tissue homogenates ranged from 90 to $109 \%$.

Cellular uptake. - Curcumin and Cur-NLC can emit green-yellow fluorescence naturally under visible light. In this study, A549 cells were seeded in a 12-well plate at a concentration of $3.0 \times 10^{5}$ cells/well $\left(37^{\circ} \mathrm{C}, 5 \% \mathrm{CO}_{2}\right)$ to monitor the cellular uptake of Cur-NLC. The cells were cultured in RPMI-1640 medium containing $10 \%(V / V)$ FBS and $1 \%(V / V)$ penicillin-streptomycin at $37^{\circ} \mathrm{C}$ and $5 \% \mathrm{CO}_{2}$. After culturing for 24 hours, $30 \mathrm{mg} \mathrm{L}^{-1} \mathrm{Cur}-$ NLC and native curcumin were added to the attached cells, respectively. Native curcumin was dissolved with DMSO for its poor water solubility (the final concentration of DMSO in the media was $\leq 0.1 \%$ ). After incubation for 2 and 4 hours in $37^{\circ} \mathrm{C}, 5 \% \mathrm{CO}_{2}$, the culture medium of each well was removed. Treated cells were carefully washed three times with $1 \times$ PBS. Cells of all groups were observed and photographed under a fluorescent microscope (Olympus IX70, Japan) at $488 \mathrm{~nm}$. 
In vitro anti-tumor assay

MTT assay. - On the day before the experiment, A549 cells were seeded in a 96-well plate $(200 \mu \mathrm{L} /$ well $)$ at a density of $4 \times 10^{4}$ cells/well. After 24 hours, a series of determined concentrations of native curcumin DMSO solution, empty NLC nanoparticles and CurNLC were added to cells for 48 hours. DMSO concentration in the medium was lower than $0.1 \%$ in order to avoid toxicity to the cells. After 48 hours of incubation, the culture medium from each well was removed and the cells were washed twice with $1 \times$ PBS. Cells were then exposed to MTT ( $5 \mathrm{mg} \mathrm{mL}^{-1}$ in PBS) for 4 hours at $37^{\circ} \mathrm{C}, 5 \% \mathrm{CO}_{2}$. The medium was carefully removed from each well, and $150 \mu \mathrm{L}$ of DMSO was added to dissolve the MTT formazan crystals for $10 \mathrm{~min}$. The amount of formazan was quantified at $490 \mathrm{~nm}$ using an enzyme-linked immunosorbent assay reader (BioTek Elx×800 microplate reader, USA) and the results were expressed as percentages relative to the result obtained with non-treated cells (cells incubated with culture medium only). All treatments were tested in triplicate, and the results were expressed as the mean value \pm SD. Cell viability (\%) was calculated by the following equation:

Cell viability $(\%)=($ optical density values for experimental groups/optical density values for control group) $\times 100 \%$

The half maximal inhibitory concentration $\left(I C_{50}\right)$ was the concentration that caused $50 \%$ inhibition of cell viability and was calculated by the Logit method (16).

Apoptosis analysis by flow cytometry. - Anticancer activity of native curcumin and CurNLC were confirmed flow cytometrically via apoptosis assay in A549 cells. A549 cells were stained with Annexin V-FITC/PI apoptosis detection kit, which detects phosphatidylserine exposed on the outer surface of the cell membrane for fluorescence-activated cell sorting (FACS) analysis. In brief, A549 cells at a density of $4 \times 10^{6}$ cells/well were seeded in 6-well plates and cultured until $75-85 \%$ confluency. Cells were treated with different concentrations of Cur-NLC and native curcumin (1.25, 5 and $10 \mathrm{mg} \mathrm{L}^{-1}$, respectively). Cells cultured with complete growth culture medium only were used as controls. After 48 hours, cells were collected by trypsinization and washed twice with cold $1 \times$ PBS in order to wash away trypsin and then centrifuged at $1000 \mathrm{rpm}$ for $5 \mathrm{~min}$. After removing the supernatant, cells were stained by adding Annexin V-FITC/PI into the binding buffer.

\section{Statistical analysis}

Stained cells were placed on ice for $15 \mathrm{~min}$ in the dark. Processed single cell suspensions were analyzed by flow cytometry (Becton Dickinson, CA, USA). Triplicates of each sample were analyzed. In the early apoptosis phase, cells are annexin $\mathrm{V}^{+} / \mathrm{PI}^{-}$. In the necrotic or late apoptosis phase, cells are annexin $\mathrm{V}^{+} / \mathrm{PI}^{+}$. Cells staining negative for both annexin $\mathrm{V}$ and PI are live cells.

Pharmacokinetic parameters were obtained using the DAS Version 2.0 Software (Chinese Pharmacological Association, China). $n$ denotes the sample size in each group. All experiments were performed in triplicate and analyzed using the one-way ANOVA test (SPSS, version 16.0) to determine the differences between profiles. Values were expressed as mean \pm SD. $p>0.05$ was considered statistically significant. 


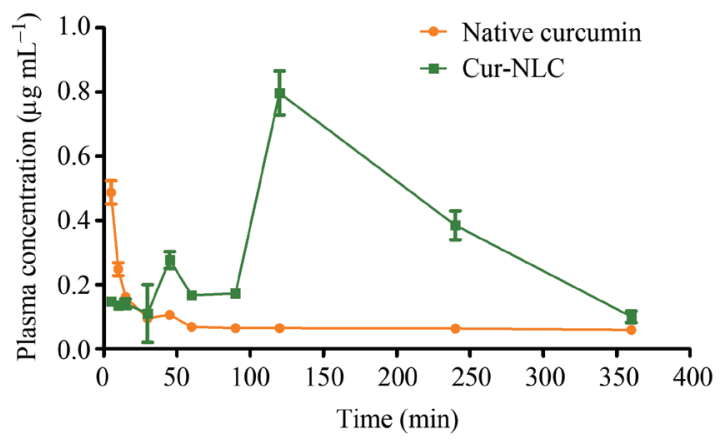

Fig. 1. Plasma concentration time profiles of native curcumin and Cur-NLC after i.p. administration of a single curcumin dose of $40 \mathrm{mg} / \mathrm{kg}$ to rats $(\bar{x} \pm \mathrm{s}, n=6)$.

\section{RESULTS AND DISCUSSION}

\section{In vivo pharmacokinetic study}

Plasma concentration time profiles and the corresponding pharmacokinetic parameters after i.p. administration of native curcumin and Cur-NLC to rats at a single curcumin dose of $40 \mathrm{mg} \mathrm{kg}^{-1}$ are, respectively, presented in Fig. 1 and Table I. The pharmacokinetic behavior of curcumin after i.p. administration of native curcumin and Cur-NLC were fitted to the non-compartment model. As shown in Table I, the pharmacokinetic parameters of curcumin after administration of Cur-NLC are markedly different from those of native curcumin. The $C_{\max }$ value of native curcumin was $0.49 \pm 0.08 \mathrm{mg} \mathrm{L}^{-1}$, and the $A U C_{0-\mathrm{t}}$ value standing for the bioavailability of native curcumin was $26.68 \pm 2.98 \mathrm{mg} \mathrm{h} \mathrm{L}^{-1}$. These results clearly illustrate the characteristic drawbacks of the i.p. administration of native curcumin, i.e. poor absorption resulting in low curcumin bioavailability. Conversely, it was observed that Cur-NLC formulation showed significantly higher curcumin $C_{\max }$ (1.61-fold) and

Table I. Pharmacokinetic parameters of native curcumin and Cur-NLC after intraperitoneal injection in rats

$$
(\bar{x} \pm s, \mathrm{n}=6)
$$

\begin{tabular}{|c|c|c|}
\hline Pharmacokinetic parameters & Native curcumin & Cur-NLC \\
\hline$A U C_{0-\mathrm{t}}\left(\mathrm{mg} \mathrm{h} \mathrm{L} \mathrm{L}^{-1}\right)$ & $26.68 \pm 2.98$ & $129.18 \pm 15.43^{* *}$ \\
\hline$M R T_{0-\mathrm{t}}(\mathrm{min})$ & $148.01 \pm 9.55$ & $171.86 \pm 12.17^{* *}$ \\
\hline$T_{\max }(\min )$ & $5 \pm 0.00$ & $120 \pm 30.22^{* *}$ \\
\hline$C_{\max }\left(\mathrm{mg} \mathrm{L}^{-1}\right)$ & $0.49 \pm 0.08$ & $0.79 \pm 0.062^{* *}$ \\
\hline 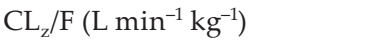 & $0.201 \pm 0.115$ & $0.161 \pm 0.077$ \\
\hline
\end{tabular}

${ }^{* *} p>0.01$ compared to the native curcumin group. AUC, area under the plasma concentration-time curve; MRT, mean residence time; $T_{\max }$ peak time; $C_{\max }$ maximum plasma concentration; $\mathrm{CL}_{\mathrm{z}} / \mathrm{F}$, total plasma clearance. 
$A U C_{0-\mathrm{t}}(2.19$-fold) compared to native curcumin, which suggested that Cur-NLC formulation could significantly improve the relative bioavailability of native curcumin. In addition, MRT were also significantly improved $(p>0.01)$. Total plasma clearance $\left(\mathrm{CL}_{\mathrm{z}} / \mathrm{F}\right)$ of Cur-NLC, as another important pharmacokinetic parameter, was much slower than that of native curcumin. Pharmacokinetic analysis showed that the relative bioavailability (F \%) of Cur-NLC was $218.42 \%$.

$$
\mathrm{F}(\%)=A U C_{\mathrm{Cur}-\mathrm{NLC}} \times 100 / A U C_{\text {Native cucumin }}
$$

Evidences have suggested that i.p. administration of chemotherapeutics has obvious advantages in pharmacokinetics, which could elevate the local drug concentration about 450-2900 times compared to systemic chemotherapy (17). A previous report indicated that nanoparticles could target the lymphatic system and act as slow-release formulations after i.p. administration in rats when compared to intravenous route (18). Based on our data from Table I, Cur-NLC formulation significantly improved the relative bioavailability of curcumin. It can be speculated that larger nanoparticles were taken up by the reticuloendothelial system (RES) or other tissues, which acted as a drug reservoir from which the drug could be slowly released, and led to markedly increased bioavailability (19). According to that theory, the improved pharmacokinetic parameters and relative bioavailability of Cur-NLC compared to native curcumin were advantageous for drug targeting to tumor tissue.

\section{Tissue distribution study}

AUC and the corresponding curcumin pharmacokinetic parameters in rat organs for the two formulations (Cur-NLC and native curcumin) are shown in Table II and Fig. 2. It can be calculated from Table II that AUC values of Cur-NLC in lung tissue are 1.54-fold higher

Table II. $\mathrm{AUC}_{0-t}$ and targeting property of native curcumin and Cur-NLC after intraperitoneal injection in rats $(\mathrm{n}=6)$

\begin{tabular}{lccccccc}
\hline \multirow{2}{*}{ Tissue } & \multicolumn{1}{c}{$A U C_{0-\mathrm{t}}$ tissue $\left(\mu \mathrm{g} \mathrm{g}^{-1} \mathrm{~h}^{-1}\right)$} & \multicolumn{2}{c}{$T_{\mathrm{e}}$} & & \\
\cline { 2 - 5 } & Cur-NLC Native curcumin & Cur-NLC Native curcumin & & & $R_{\mathrm{e}}$ \\
\hline Heart & $7.66 \pm 0.90$ & $22.21 \pm 4.91$ & 0.05 & 0.16 & 0.18 & 0.34 \\
Liver & $93.68 \pm 12.05$ & $31.78 \pm 7.97$ & 1.12 & 0.24 & 1.95 & 2.94 \\
Spleen & $30.42 \pm 6.16$ & $38.84 \pm 9.21$ & 0.21 & 0.31 & 0.45 & 0.78 \\
Lung & $16.23 \pm 2.09$ & $10.02 \pm 1.83$ & 0.10 & 0.07 & 1.08 & 1.61 \\
Kidney & $8.24 \pm 0.99$ & $10.06 \pm 2.72$ & 0.05 & 0.07 & 0.36 & 0.81 \\
Stomach & $6.93 \pm 0.85$ & $26.46 \pm 7.64$ & 0.04 & 0.19 & 0.06 & 0.26 \\
Small & $6.34 \pm 0.68$ & $15.23 \pm 3.11$. & 0.04 & 0.10 & 0.13 & 0.41 \\
intestine & & & & & & & \\
\hline
\end{tabular}

$T_{\mathrm{e}}$ - targeting efficiency, $R_{\mathrm{e}}$ - relative targeting efficiency, $C_{\mathrm{e}}$ - ratio of peak plasma concentration 

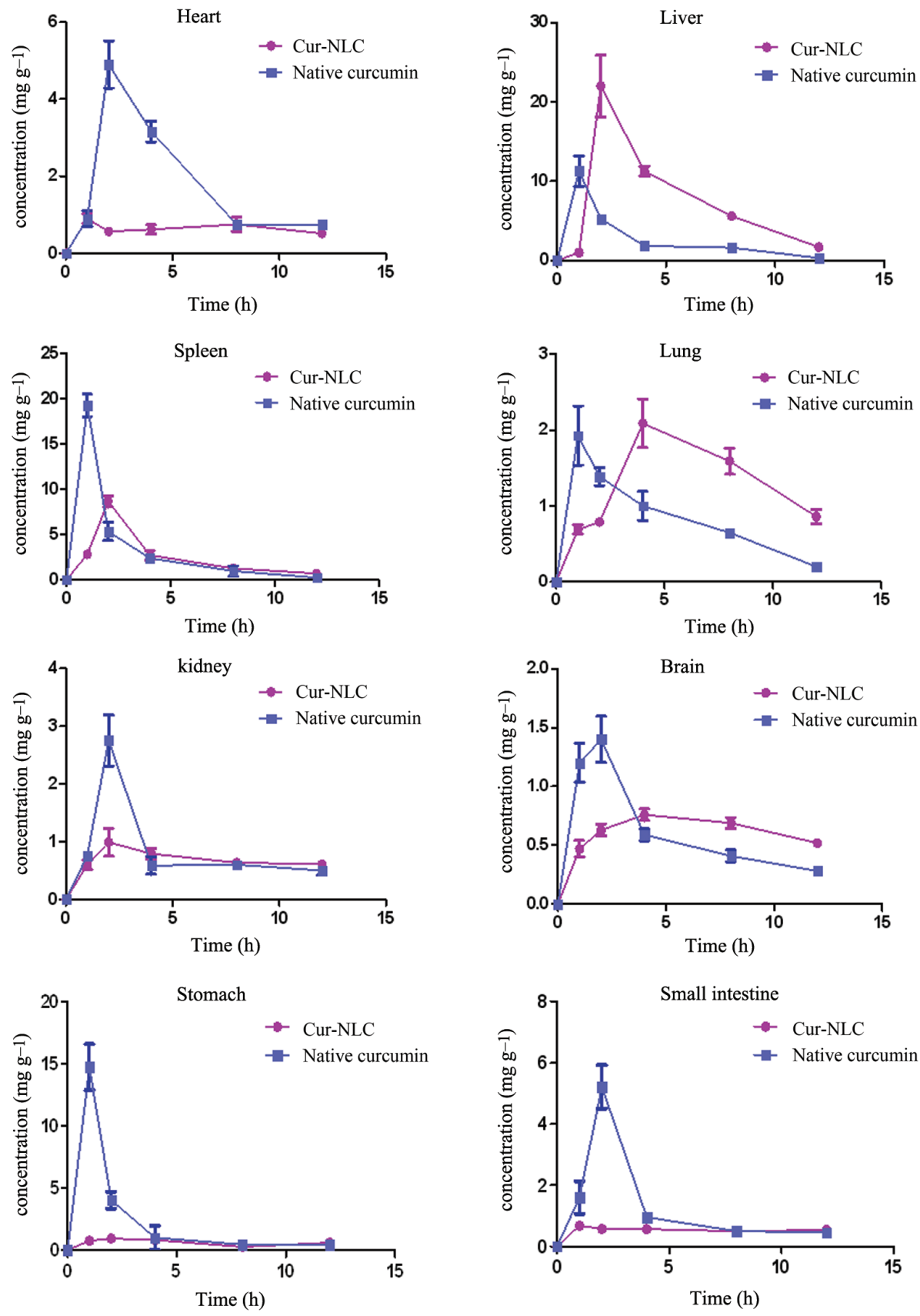

Fig. 2. Curcumin tissue distribution curves after i.p. administration of native curcumin and Cur-NLC in a curcumin dose of $40 \mathrm{mg} \mathrm{kg}^{-1}$. 
than those of native curcumin. In addition, the AUC values of Cur-NLC markedly decreased in the heart, spleen, kidney, stomach and small intestine in comparison with native curcumin. As shown in Fig. 2, the curcumin concentration and $A U C_{0-t}$ value in the lung both increase in the case of nanoformulation, while this does not occur in other organs, except for the liver. The concentration of curcumin was negligible in lung tissue 12 hours after the treatment in the native curcumin group, while curcumin was still measurable in the CurNLC group. In comparison with native curcumin, the ratio of peak plasma concentration $\left(C_{\mathrm{e}}\right)$ and relative uptake rate equivalent $\left(R_{\mathrm{e}}\right)$ of Cur-NLC were both higher than in the lung. In addition, targeting efficiency $\left(T_{\mathrm{e}}\right)$ was also increased in the lung, which indicated that Cur-NLC could increase significantly the curcumin level in the lung. Thus, Cur-NLC showed obvious lung-targeting (Table II). The values of $R_{\mathrm{e}}, T_{\mathrm{e}}$ and $C_{\mathrm{e}}$ seemed higher in the liver than in the lung when rats were treated with Cur-NLC. The possible reason was that liver was the principal organ for metabolizing and disposing of Cur-NLC, which led to CurNLC being accumulated to a greater extent in the liver tissue than in other tissues.

$$
\begin{gathered}
C_{\mathrm{e}}=\left(C_{\mathrm{max}}\right)_{\text {Cur-NLC }} /\left(C_{\mathrm{max}}\right)_{\text {Native cucumin }} ; R_{\mathrm{e}}=\left(A U C_{\text {Tissue }}\right)_{\text {Cur-NLC }} /\left(A U C_{\text {Tissue }}\right)_{\text {Native cucumin }} ; \\
T_{\mathrm{e}}=(A U C)_{\text {target organ }} /(A U C)_{\text {non-target organ. }}
\end{gathered}
$$

Nanoparticles can promote particle recognition of the RES by organs such as liver, lung and spleen by opsonization processes $(20,21)$. This study revealed that uptake of nanoparticles from capillaries of the parietal peritoneum into the target organ might lead to CurNLC distributed to lung tissue more intensively than native curcumin. High curcumin concentration in target tissue is vital for curcumin to have pharmacological activity.

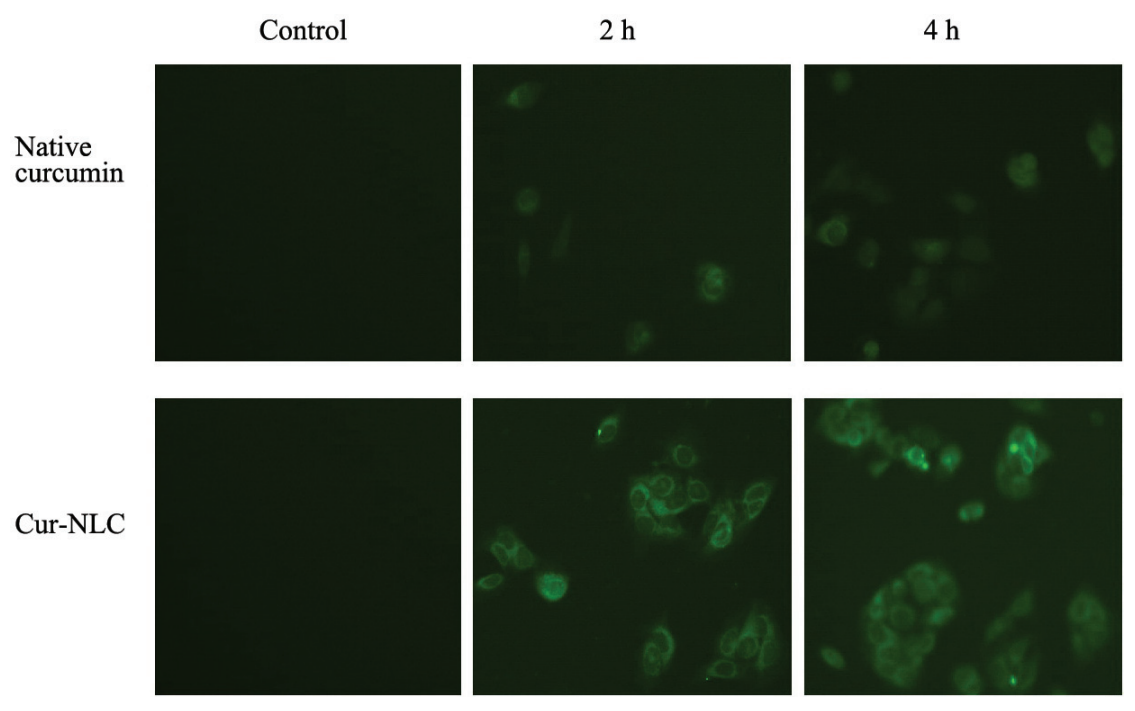

Fig. 3. Fluorescent images of A549 cells after 2- and 4-hour treatment with Cur-NLC and native curcumin. Original magnification $\times 400$. 


\section{In vitro cellular uptake}

Fig. 3 shows a significant difference in cell uptake between Cur-NLC and native curcumin. The intrinsic green-yellow fluorescence of curcumin was observed after cellular uptake. Hours of incubation were sufficient for A549 cells to take up nanoparticles, which were then localized in the cytoplasm. It was obvious that A549 cells treated for 2 hours with native curcumin and Cur-NLC showed weaker bright yellow fluorescence than the cells treated for 4 hours. Control cells and empty NLC treated cells showed no fluorescence. Fluorescent microscopy demonstrated that the uptake efficiency of curcumin by A549 cells was enhanced when delivered by NLC. These results indicate that encapsulation within NLC might be a useful tool for drug delivery to lung cancer cells.

A549 cells could internalize Cur-NLC more effectively than native curcumin under the same conditions. These results could be attributed to the small size of Cur-NLC nanoparticles and zeta potential, which influence the particle stability, cellular uptake, clearance and intracellular trafficking $(22,23)$. Cellular uptake of nanoparticles, as a significant event, could be mediated through endocytosis rather than passive diffusion (24).

In vitro cytotoxicity of Cur-NLC

Using the MTT assay, cell toxicity of native curcumin and Cur-NLC against A549 cells was determined. The results showed that both native curcumin and Cur-NLC significantly reduced cell viability against A549 cells in a similar dose dependent manner. As shown in Fig. 4, the decrease in cell viability of A549 cells was more pronounced in the case of Cur-NLC than in the case of native curcumin treatment. Significant difference in cell viability between native curcumin and Cur-NLC was measured at four different curcumin concentrations $\left(2.5,5,10\right.$ and $\left.20 \mathrm{mg} \mathrm{L}^{-1}\right)$ after 48 hours of incubation. In vitro half maximal inhibitory concentration $\left(I C_{50}\right)$ was used as a quantitative measure of cytotoxicity induced by a chemotherapeutic drug. $I C_{50}$ values were calculated according to the obtained

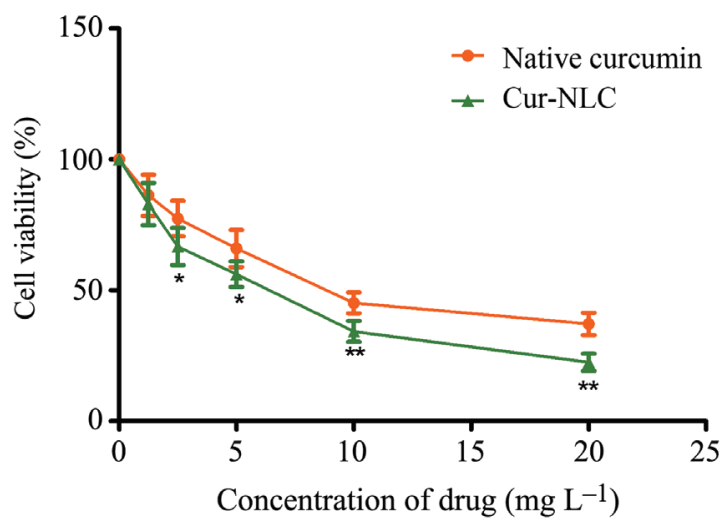

Fig. 4. In vitro cytotoxicity of native curcumin and Cur-NLC against A549 cells $(\bar{x} \pm \mathrm{s}, n=6)$. Data are the means of 3 independent experiments. ${ }^{*} p<0.05,{ }^{* *} p<0.01$ compared to the same concentration of native curcumin. 
sigmoidal curves of A549 cells. The $I C_{50}$ values of Cur-NLC and native curcumin are shown in Table III. It was obvious that Cur-NLC, at an equivalent dose, exhibited higher cytotoxicity than native curcumin. Cur-NLC was about 1.73 times more effective than native curcumin in A549 cells.

Table III. IC50 values of native curcumin and Cur-NLC in A549 cells as measured by the MTT assay

\begin{tabular}{lcc}
\hline Tumor cells & Native curcumin $I C_{50}\left(\mathrm{mg} \mathrm{L}^{-1}\right)$ & Cur-NLC IC \\
50 & $\left(\mathrm{mg} \mathrm{L}^{-1}\right)$ \\
A549 & $9.81 \pm 1.29$ & $5.66 \pm 0.41^{\mathrm{a}}$ \\
\hline
\end{tabular}

${ }^{\text {a }} p>0.01$ compared to native curcumin $I C_{50}$

a)

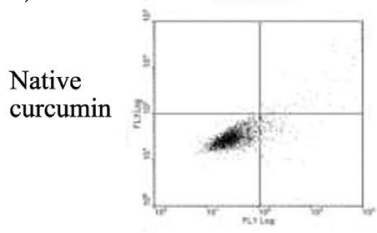

Cur-NLC

b)

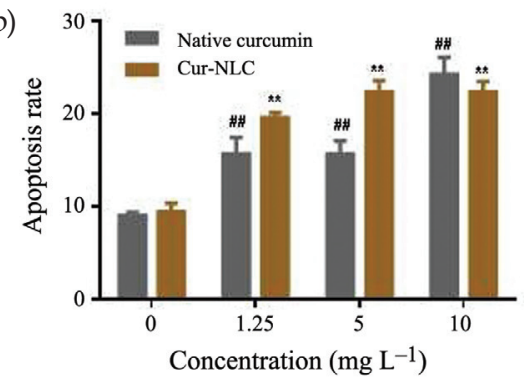

$1.25 \mathrm{mg} \mathrm{L}^{-1}$
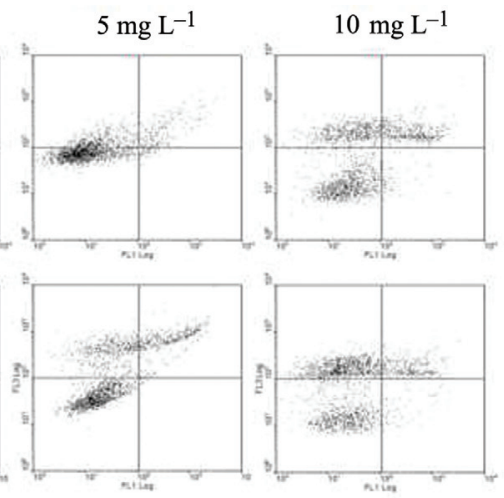

c)

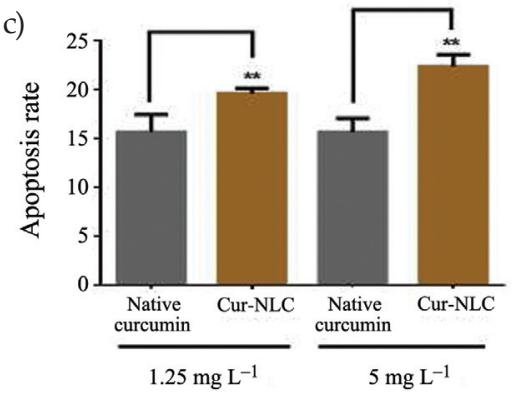

Fig. 5. Effect of native curcumin and Cur-NLC in different dosages on A549 cell apoptosis. a) A549 cells were treated with Cur-NLC and native curcumin. The apoptosis rate was the sum of the early and late apoptosis phases. b) Bar graph shows the effect of Cur-NLC and native curcumin on apoptosis of A549 cells $(\bar{x} \pm \mathrm{s}, n=3)$. ${ }^{\# *} p<0.01$ compared to the control group; ${ }^{* *} p<0.01$ compared to the empty nanoparticle treated group. c) Apoptosis rate of Cur-NLC treatment showed a more significant difference than that of native curcumin groups $(\bar{x} \pm s, n=3) .{ }^{* *} p<0.01$ compared to the native curcumin group. 
Drug stability and the duration of intracellular drug accumulation by nanoparticle uptake are correlated with cytotoxicity A549 (25). It is known that the free form of the drug diffuses across the cell membrane when used as a solution. Therefore, further entry will be rapidly confined when reaching saturation inside the protoplasm, which showed weak cytotoxicity for a very short time $(25,26)$. However, Cur-NLC as a nanocarrier had abundant availability inside the cell by endocytosis and encapsulated curcumin exerted sustained cytotoxicity. Our cytotoxicity results confirmed that Cur-NLC, at an equivalent curcumin dose, exhibited stronger cytotoxicity than native curcumin. Namely, Cur-NLC led to higher cell death rate with lower $I C_{50}$ when compared to native curcumin. The difference in the uptake profile might be the reason for stronger cytotoxicity of Cur-NLC.

\section{Cur-NLC induce apoptosis in the A549 cell line in vitro}

Consistent with the MTT assay, FACS analysis showed a dose-dependent increase in the proportion of apoptotic cells in Cur-NLC treatments. A549 cell apoptosis was quantified by annexin-V/PI staining (FACS analysis) after the treatment with native curcumin or Cur-NLC (1.25, 5 and $\left.10 \mathrm{mg} \mathrm{L}^{-1}\right)$ for 48 hours. Apoptotic cell externalize phosphatidylserine on the outer layer of the cell membrane to which Annexin-V binds. This flow cytometry method can discriminate the percentage of cells in early (Annexin-V-positive cells) and late apoptosis (Annexin-V and PI-positive cells) from live cells (unstained by either fluorochrome) (Fig. 5). As shown in Fig. 5c, flow cytometric analysis demonstrates that Cur-NLC $\left(1.25 \mathrm{mg} \mathrm{L}^{-1}\right)$ treated A549 cells had a higher apoptosis rate, i.e. $19.61 \%$ in apoptosis compared to $15.67 \%$ in native curcumin $\left(1.25 \mathrm{mg} \mathrm{L}^{-1}\right)$ treated cells, and the percentage of apoptotic cells increased from $15.65 \%$ in the case of native curcumin $\left(5 \mathrm{mg} \mathrm{L}^{-1}\right)$ treatment to $22.37 \%$ in the case of Cur-NLC $\left(5 \mathrm{mg} \mathrm{L}^{-1}\right)$ treatment. However, there was no statistical difference in the percentage of apoptotic cells between the treatments when cells were treated with the highest curcumin concentration $\left(10 \mathrm{mg} \mathrm{mL}^{-1}\right)$. The reason was not found. Further studies should be conducted in order to obtain more data on the potential of CurNLC to induce apoptosis. These data revealed that both necrosis and apoptosis contributed to Cur-NLC induced death of A549 cells, and Cur-NLC treated A549 cells showed a higher apoptosis rate than that of native curcumin.

Growing evidence revealed that apoptosis was essential for cancer therapy and represents a mechanism to counteract neoplastic development $(27,28)$. In recent years, accumulating studies on apoptosis have demonstrated that curcumin was responsible for inducing apoptosis signals in various tumor tissues, including lung cancer (27). Our study showed that Cur-NLC induced more apoptosis than native curcumin, which was consistent with the results of the cytotoxicity assay. It is well known that increasing the concentration of curcumin in the lung favors a therapeutic effect in lung cancer. In our study, we found that Cur-NLC could easily translocate into lung tissue and remain in this organ for a longer time, which would be essential for its anticancer effects in lung cancer. Based on these facts, NLC is an effective delivery system for curcumin in lung cancer treatment.

\section{CONCLUSIONS}

This study has revealed that NLC has markedly improved the pharmacokinetics and tissue distribution of curcumin after i.p. administration. The results of A549 cellular up- 
take test showed that the cellular uptake efficiency of Cur-NLC was higher than that of native curcumin. In vitro cytotoxicity assay and apoptosis analysis implied that Cur-NLC showed stronger anticancer activity than native curcumin by inhibiting proliferation and inducing apoptosis against A549 cells. We could draw the conclusion that these nanostructured lipid curcumin carriers possessed not only improved curcumin pharmacokinetic properties but also improved the anticancer activity in lung A549 cells. Therefore, CurNLC could serve as a promising tool in lung cancer treatment. Further investigation is required to gain full understanding of its beneficial effect in preventing the progression of lung cancer.

Acknowledgments. - This research was supported by the Anhui Provincial traditional Chinese medicine scientific research project (2014zy79) and scientific research project of social development plans of Hefei City in 2013 [Hefei, 2013, No 25(46)]. The authors acknowledge the assistance in conducting this study of the students of the Pharmacokinetics Lab, Anhui University of Chinese Medicine.

\section{REFERENCES}

1. J. Y. Park and S. H. Jang, Epidemiology of lung cancer in Korea: Recent trends, Tuberc. Respir. Dis. (Seoul). 79 (2016) 58-69; DOI: 10.4046/trd.2016.79.2.58.

2. S. C. Gupta, S. Patchva, W. Koh and B. B. Aggarwal, Discovery of curcumin, a component of golden spice, and its miraculous biological activities, Clin. Exp. Pharmacol. Physiol. 39 (2012) 283299; DOI: 10.1111/j.1440-1681.2011.05648.x.

3. H. Mahammedi, E. Planchat, M. Pouget, X. Durando, H. Curé, L. Guy, I. Van-Praagh, L. Savareux, M. Atger, M. Bayet-Robert, E. Gadea, C. Abrial, E. Thivat, P. Chollet and J. C. Eymard, The new combination docetaxel, prednisone and curcumin in patients with castration-resistant prostate cancer: A Pilot Phase II Study, Oncology 90 (2016) 69-78; DOI: 10.1159/000441148.

4. S. C. Gupta, G. Kismali and B. B. Aggarwal, Curcumin, a component of turmeric: from farm to pharmacy, Biofactors 39 (2013) 2-13; DOI: 10.1002/biof.1079.

5. D. Perrone, F. Ardito, G. Giannatempo, M. Dioguardi, G. Troiano, L. Lo Russo, L. A. De, L. Laino and L. Lo Muzio, Biological and therapeutic activities, and anticancer properties of curcumin, Exp. Theor. Med. 10 (2015) 1615-1623.

6. M. Kanai, Y. Otsuka, K. Otsuka, M. Sato, T. Nishimura, Y. Mori, M. Kawaguchi, E. Hatano, Y. Kodama, S. Matsumoto, Y. Murakami, A. Imaizumi, T. Chiba, J. Nishihira and H. Shibata, A phase I study investigating the safety and pharmacokinetics of highly bioavailable curcumin (Theracurmin) in cancer patients, Cancer Chemother. Pharmacol. 71 (2013) 1521-1530; DOI: 10.1007/s00280013-2151-8.

7. H. A. Hazzah, R. M. Farid, M. M. Nasra, M. A. El-Massik and O. Y. Abdallah, Lyophilized sponges loaded with curcumin solid lipid nanoparticles for buccal delivery: Development and characterization, Int. J. Pharm. 492 (2015) 248-257; DOI: 10.1016/j.ijpharm.2015.06.022.

8. F. Foglietta, L. Serpe, R. Canaparo, N. Vivenza, G. Riccio, E. Imbalzano, P. Gasco and G. P. Zara, Modulation of butyrate anticancer activity by solid lipid nanoparticle delivery: an in vitro investigation on human breast cancer and leukemia cell lines, J. Pharm. Pharm. Sci. 17 (2014) 231-247.

9. N. Naseri, H. Valizadeh and P. Zakeri-Milani, Solid lipid nanoparticles and nanostructured lipid carriers: structure, preparation and application, Adv. Pharm. Bull. 5 (2015) 305-313; DOI: 10.15171/ apb.2015.043.

10. R. H. Müller, R. Shegokar and C. M. Keck, 20 years of lipid nanoparticles (SLN and NLC): Present state of development and industrial applications, Curr. Drug. Discov. Technol. 8 (2011) 207-227. 
11. S. Selvamuthukumar and R. Velmurugan, Nanostructured lipid carriers: a potential drug carrier for cancer chemotherapy, Lipids Health Dis. 11 (2012) 159; DOI: 10.1186/1476-511X-11-159.

12. J. Chen, W. T. Dai, Z. M. He, L. Gao, X. Huang, J. M. Gong, H.Y. Xing and W. D. Chen, Fabrication and Evaluation of Curcumin-loaded Nanoparticles Based on Solid Lipid as a New Type of Colloidal Drug Delivery System, Indian J. Pharm. Sci. 75 (2013) 178-184.

13. W. H. Lee, C. Y. Loo, P. M. Young, D. Traini, R. S. Mason and R. Rohanizadeh, Recent advances in curcumin nanoformulation for cancer therapy, Expert Opin. Drug Deliv. 11 (2014) 1183-1201; DOI: 10.1517/17425247.2014.916686.

14. Q. Y. Chen, Y. Zheng, D. M. Jiao, F.Y. Chen, H. Z. Hu, Y. Q. Wu, J. Song, J. Yan, L. J. Wu and G. Y. Lv, Curcumin inhibits lung cancer cell migration and invasion through Rac1-dependent signaling pathway, J. Nutr. Biochem. 25 (2014) 177-185; DOI: 10.1016/j.jnutbio.2013.10.004.

15. M. Cao, L. Ren and G. Chen, Formulation optimization and ex vivo and in vivo evaluation of celecoxib microemulsion-based gel for transdermal delivery, AAPS PharmSciTech. (2016) Dec 2. [Epub ahead of print].

16. C. Hasovits and S. Clarke, Pharmacokinetics and pharmacodynamics of intraperitoneal cancer chemotherapeutics, Clin. Pharmacokinet. 51 (2012) 203-224; DOI: 10.2165/11598890-00000000000000 .

17. S. K. Williamson, G. A. Johnson, H. A. Maulhardt, K. M. Moore, D. S. McMeekin, T. K. Schulz, G. A. Reed, K. F. Roby, C. B. Mackay, H. J. Smith, S. J. Weir, J. A. Wick, M. Markman, G. S. diZerega, M. J. Baltezor, J. Espinosa and C. J. Decedue, A phase I study of intraperitoneal nanoparticulate paclitaxel $\left(\operatorname{Nanotax}^{\circledR}\right)$ in patients with peritoneal malignancies, Cancer Chemother. Pharmacol. 75 (2015) 1075-1087; DOI: 10.1007/s00280-015-2737-4.

18. P. Maincent, P. Thouvenot, C. Amicabile, M. Hoffman, J. Kreuter, P. Couvreur and J. P. Devissaguet, Lymphatic targeting of polymeric nanoparticles after intraperitoneal administration in rats, Pharm. Res. 9 (1992) 1534-1539.

19. S. Kommareddy, S. B. Tiwari and M. M. Amiji, Long-circulatin polymeric nanovectors for tumorselective gene delivery, Technol. Cancer Res. Treat. 4 (2005) 615-625.

20. R. Tiwari and K. Pathak, Nanostructured lipid carrier versus solid lipid nanoparticles of simvastatin: comparative analysis of characteristics, pharmacokinetics and tissue uptake, Int. J. Pharm. 415 (2011) 232-243; DOI: 10.1016/j.ijpharm.2011.05.044.

21. M. Fang, Y. Jin, W. Bao, H. Gao, M. Xu, D. Wang, X. Wang, P. Yao and L. Liu, In vitro characterization and in vivo evaluation of nanostructured lipid curcumin carriers for intragastric administration, Int. J. Nanomedicine 7 (2012) 5395-5404; DOI: 10.2147/IJN.S36257.

22. D. Zheng, W. Dai, D. Zhang, C. Duan, L. Jia, Y. Liu and Q. Zhang, In vivo studies on the oridoninloaded nanostructured lipid carriers, Drug Deliv. 19 (2012) 286-291;DOI:10.3109/10717544.2012.704096.

23. C. Mohanty and S. K. Sahoo, The in vitro stability and in vivo pharmacokinetics of curcumin prepared as an aqueous nanoparticulate formulation, Biomaterials 31 (2012) 6597-6611. DOI: 10.1016/j.biomaterials.2010.04.062.

24. H. Rosen and T. Abribat, The rise and rise of drug delivery, Nat. Rev. Drug Discov. 4 (2005) 381-385.

25. D. Breznan, D. D. Das, J. S. O’Brien, C. MacKinnon-Roy, S. Nimesh, N. Q. Vuong, S. Bernatchez, N. DeSilva, Hill M, P. Kumarathasan, R. Vincent, Differential cytotoxic and inflammatory potency of amorphous silicon dioxide nanoparticles of similar size in multiple cell lines, Nanotoxicology. 1 (2017) 1-45. DOI: 10.1080/17435390.2017.1287313.

26. J. H. Duan, Y. D. Zhang, S. W. Han, Y. X. Chen, B. Li, M. M. Liao, W. Chen, X. M. Deng, J. F. Zhao and B. Y. Huang, Synthesis and in vitro/in vivo anti-cancer evaluation of curcumin-loaded chitosan/poly(butyl cyanoacrylate) nanoparticles, Int. J. Pharm. 400 (2010) 211-220. 
F. Wang et al.: Pharmacokinetic studies and anticancer activity of curcumin-loaded nanostructured lipid carriers, Acta Pharm. 67 (2017) $357-371$.

27. S. Lev-Ari, L. Strier, D. Kazanov, O. Elkayam, D. Lichtenberg, D. Caspi and N. Arber, Curcumin synergistically potentiates the growth-inhibitory and pro-apoptotic effects of celecoxib in osteoarthritis synovial adherent cells, Rheumatology (Oxford) 45 (2006) 171-177.

28. S. Lev-Ari, A. Vexler, A. Starr, M. Ashkenazy-Voghera, J. Greif, D. Aderka and R. Ben-Yosef, Curcumin augments gemcitabine cytotoxic effect on pancreatic adenocarcinoma cell lines, Cancer Invest. 25 (2007) 411-418. 